\title{
Characteristics and outcomes of critically ill children transported by ambulance in a Turkish prehospital system: a multicenter prospective cohort study
}

\author{
Eylem Ulaş Saz ${ }^{1 \oplus}$, Caner Turan ${ }^{1 \oplus}$, Murat Anı1 ${ }^{2 \odot}$, Alkan Bal ${ }^{2 \odot}$, Gamze Gökalp ${ }^{2 \odot}$, \\ Hayri Levent Yılmaz ${ }^{3 \oplus}$, Sinem Sarı Gökay ${ }^{3 \odot}$, Tuğçe Çelik ${ }^{3 \odot}$, Nilden Tuygun ${ }^{4 \odot}$, \\ Halise Akça ${ }^{4 \oplus}$, Deniz Tekin ${ }^{5}$, Sinan Oğuz ${ }^{5 \odot}$, Tanju Çelik ${ }^{6}$, Özlem Tekşam ${ }^{7 \odot}$, \\ Ayşe Gültekingil Keser ${ }^{7 \odot}$, Gülser Esen Besli ${ }^{8}$, Murat Duman $^{9 \odot}$, Ali Yurtseven ${ }^{1 \odot}$ \\ ${ }^{1}$ Division of Pediatric Emergency, Department of Pediatrics, Ege University Faculty of Medicine, Izmir; ${ }^{2}$ Division of Pediatric \\ Emergency, Department of Pediatrics, Tepecik Teaching and Research Hospital, Izmir; ${ }^{3}$ Division of Pediatric Emergency, Department \\ of Pediatrics, Çukurova University Faculty of Medicine, Adana; ${ }^{4}$ Division of Pediatric Emergency, Department of Pediatrics, Dr Sami \\ Ulus Maternity and Children's Health and Diseases Training and Research Hospital, Ankara; ${ }^{5}$ Division of Pediatric Emergency, \\ Department of Pediatrics, Ankara University Faculty of Medicine, Ankara; ${ }^{6}$ Division of Pediatric Emergency, Department of Pediatrics, \\ Dr.Behçet Uz Children's Disease and Surgery Training and Research Hospital, Izmir; ' Division of Pediatric Emergency, Department \\ of Pediatrics, Hacettepe University Faculty of Medicine, Ankara; ${ }^{8}$ Division of Pediatric Emergency, Department of Pediatrics, Göztepe \\ Training and Research Hospital, İstanbul Medeniyet University, İstanbul; ${ }^{9}$ Division of Pediatric Emergency, Department of Pediatrics, \\ Dokuz Eylul University Faculty of Medicine, İzmir, Turkey.
}

\begin{abstract}
Background. The most underdeveloped area in the care of critically-ill-children (CIC) is the prehospital period. Appropriate prehospital assessment and life-saving-interventions (LSI) of this population are challenging and require dedicated resources to ensure the best outcomes. We aimed to determine the characteristics and outcomes of CIC transported to the Turkish Pediatric Emergency Departments (EDs). The frequency and distribution of LSI administered by prehospital providers on route and in the EDs were also investigated.

Methods. This prospective study was conducted at 4 metropolitan cities and 9 tertiary pediatric EDs between August 2014-August 2015. A survey based study evaluated all CIC who were brought by ambulance to the participant EDs. CIC were defined as a patient who requires LSI or needs intensive care admission for any reason. Patient demographics, clinical features, reason for transport, performed procedures in the ambulance or ED were sought. Finally, the short-term outcomes of transported CIC and transport-associated risks were analyzed.
\end{abstract}

Results. During the study period, a total 2094 children were brought by ambulance to all participant EDs. Only $227(10.8 \%)$ of them were critically-ill. Emergency Medical Services (EMS) providers were less likely to perform procedures in CIC if they were staffed with paramedics $(\mathrm{p}<0.001)$. Most procedures were performed on children aged one or older $(\mathrm{p}<0.001)$. No procedure was performed in the ambulance for nearly one fourth of patients who received LSI in the EDs. If the EMS did not have a physician, prehospital providers were less likely to provide immediate LSIs $(\mathrm{p}<0.001)$. CIC were more likely referred from secondary/tertiary care hospitals. The short-term mortality rate was higher if

Caner Turan

caner.turan@ege.edu.tr

Received 12th July 2019, revised 30st May 2020, accepted 31st May 2020.

This sudy was presented at the "10th European Congress of Emergency Medicine (EuSEM), Vienna, Austria, 1st 5th October, 2016" as a Poster presentation and the "XIII. National Pediatric Emergency Care and Intensive Care Congress, Izmir, Turkey, 5th-8th Sept, 2016" - as an oral presentation. the ambulance was staffed by only paramedics.

Conclusion. This study demonstrated that Turkish prehospital pediatric emergency care is deficient. We offer a clinical overview of pediatric emergencies to aid EMS directors, policymakers, and ED directors in planning the care of CIC.

Key words: prehospital care, critically ill children, ambulance, emergency medical service, paramedic. 
The concept of emergency medical service (EMS) consists of many areas of emergency care, including the primary evaluation, management, and transport of patients from the field of an injury or illness to their arrival at an emergency care facility (the out-of-hospital or prehospital care), as well as the management within the emergency department (ED) and intensive care unit (ICU).

Significant improvement in EMS systems have been achieved in the United States of America (USA) since the 1970s, especially for the adult population. ${ }^{1}$ Early systems have been designed to provide rapid intervention in case of cardiac arrest and rapid transport for motor vehicle crash victims among adults. Since the most significant causes of mortality in the pediatric population are trauma and poisoning, it is important to consider the effects of the 'transport' stage on outcome. Previous studies have reported poor improvement in prognosis among pediatric patients despite the development of a modern EMS., ${ }^{2,3}$ This is primarily a result of the higher proportions of adult emergencies and thus the higher rate of adult patients for whom the EMS providers are involved in the early care. Providing medical care for critically ill children (CIC) requires a different skillset from those required for adult providers, including attention to the unique characteristics and needs of the pediatric population.

The implementation of EMS for children significantly reduced the mortality and improved outcomes in pediatric patients with trauma and other medical emergencies in developed countries.-6 In Turkey, almost all cities have EMS, which consists of pre-hospital medical care and transport to a medical facility. ${ }^{7}$ All EMS demand is made by calls to an emergency number which is 112 in Turkey and similar to some European countries. EMS was primarily developed for adults during the 1990s in our country and this improved the outcome of sudden cardiac arrest. However, there is a significant lack of appropriate investment in EMS infrastructure for CIC. There is a paucity of data concerning pediatric prehospital care outcomes. In our country, information concerning the number of CIC utilizing the EMS system is unknown, thus, could benefit from an optimal system designed to meet their needs.

We aimed to identify the frequency and causes of prehospital pediatric emergencies and important prognostic factors associated with transport by EMS of CIC. The percentage of immediate life-saving interventions (LSI) / nonLSI performed by either EMS providers or ED physicians and their effects on outcomes were also investigated.

\section{Material and Methods}

\section{Study design}

According to the Address Based Population Registration System (ABPRS) released by the Turkish Statistical Institute in 2014, Turkey had a total population of 77.695 million, with 22.838 million children aged 0-17.

This prospective study was conducted in four metropolitan cities and nine tertiary pediatric EDs in Turkey. Transported CIC to one of the participant ED's (4 training and teaching hospitals and 5 University Hospitals) between 1 August 2014, and 1 August 2015 were enrolled in the study. A data collection form was prepared by the principle author and sent to all nine EDs before patient enrollment began. The local ethical committee of Ege University (13-4.1/14) approved this study.

\section{EMS Present practice}

The Ministry of Health Emergency Medical Services General Bureau published the National EMS Scope of Practice Model to provide general recommendations around the scope of practice and licensure. ${ }^{8}$ In the most current version of the Scope of Practice Model there are three designations for EMS professionals: Emergency Medical Responders (EMR), Ambulance and emergency care technicians (AEMT), and Paramedics. As stated within the document, their differing roles are; 
1. EMR: The primary focus is to initiate immediate life-saving care to critical patients who access the EMS. The scope of EMRs includes the following skills: airway positioning and bag valve mask ventilation, hemorrhage control, automated electronic defibrillator (AED) defibrillation, and cardiopulmonary resuscitation (CPR).

2. AEMT: To provide basic and limited advanced emergency medical care and transportation for critical and emergent patients who access the EMS. AEMTs typicallydoallanEMRdoeswith theaddition of providing medications such as oxygen, sublingual nitro, inhaled medications, oral glucose, EpiPen ${ }^{\circledR}$ administration; taking vital signs; extremity splinting; and spinal immobilization, may perform electrocardiograms (ECGs), endotracheal intubation, nasogastric tube placement, determination of death, defibrillation and pacing, needle thoracotomy, aspiration of newborn meconium, intravenous line placement, and drug administration.

3. Paramedic: To provide advanced emergency medical care for critical and emergent patients who access the emergency medical system. Additionally, they may perform; needle cricothyrotomy, intubation, and 12 lead ECG interpretation.

\section{Study Population and Data Collection}

The physician on shift from the participant ED completed the data collection form for each patient. Our age groups were structured according to the Pediatric Advanced Life Support (PALS) guideline for age groups; group 1: 0-28 days, group 2: 28 days-1year, group 3: 1 -10 years old and group 4: > 10 years. The data collection form included information on; demographics, clinical features, triage level, information calls to receiving facility, and reason for transportation. The referring physicians specialties, intervention type provided by EMS or by ED staff were also recorded. CIC was defined as a patient who requires LSI or needs intensive care admission for any reason. Finally, the short-term outcomes of transported CIC and transport-associated risks were analyzed. Informed consent was obtained from the participants families.

\section{Statistical analysis}

Statistics Package for the Social Sciences 22.0 software (SPSS Inc.; Chicago, IL, ABD) was used for statistical analysis. Continuous data was represented by mean and standard deviation. Categorical variables were expressed by frequency and cross tables. The chi-square test (or Fisher's exact probability test) was used to compare demographics in terms of age groups, and time and month of presentation. MannWhitney $U$ or t-test was performed for two independent groups. $p$ values lower than 0.05 were regarded as statistically significant.

\section{Results}

During the study period, a total of 2094 patients were transported to the 9 different EDs of which 227 were CIC (10.8\%). Most patients $(90 \%)$ did not receive LSIs at the ED. Of the participants $53 \%$ were boys and the median age was 5.5 years. The higher percentage of CIC was in group 3 (1-10 years) and group 4 (>10 years) $48.9 \%$, and $26.4 \%$ respectively. Only a low rate $(n=46,20.3 \%)$ of patients were transported by ambulance were accompanied by a physician (Table I). Table I shows the frequency and distribution of EMS transfer sites. Secondary care hospitals served as the main referral site in $57.3 \%$ of the cases, and a small proportion of the total number which was $10.6 \%(n=24)$ were brought from home. Pediatricians were the most common physicians who gave the interfacility transport decision (48.9\%), and the receiving facility did not receive information calls for more than half of the patients (39.2\%) before arrival.

The most common diagnoses were toxicological, traumatic and respiratory emergencies with the rate of $22.5 \%, 19.4 \%$ and $15.8 \%$, respectively (Table II). Children with trauma and toxicity 
Table I. Characteristics of critically-Ill-children and EMS crew.

\begin{tabular}{lc}
\hline & $\mathrm{n}(\%)$ \\
\hline Sex (Male) & $121(53.3)$ \\
Age, median (years) & 5.5 \\
$0-28 \mathrm{~d}$ & $54(2.6)$ \\
$28 \mathrm{~d}-1$ & $328(15.7)$ \\
$1-10$ & $1048(50)$ \\
$10-18$ & $664(31.7)$ \\
Distance (km), mean (min-max) & $63.8(2.8-800)$ \\
Information call & \\
No & $89(39.2)$ \\
Yes & $138(60.8)$ \\
Referred by & \\
Family-care physician & $6(2.6)$ \\
Pediatrician & $111(48.9)$ \\
Other physician & $60(26.4)$ \\
Family or scene & $50(22)$ \\
Transport from & \\
Home & $24(10.6)$ \\
Field & $26(11.5)$ \\
Primary care hospital & $5(2.2)$ \\
Secondary care hospital & $130(57.3)$ \\
Tertiary care hospital & $32(14.1)$ \\
Other & $10(4.4)$ \\
EMS Staff & \\
Physician & $46(20.3)$ \\
Paramedic + AEMT & $181(79.7)$ \\
\hline
\end{tabular}

EMS: emergency medical service, SD: standard deviation, $\mathrm{km}$ : kilometer, min: minimum, max: maximum, AEMT: ambulance and emergency care technician.

were more likely to be older (1-10 years: $43.2 \%$ and $>10$ years: $71.7 \%)$. In contrast, transferred patients who had other medical emergencies were more likely to be younger than one year old (Fig. 1). Most of the intoxications (66.7\%) occurred by mouth, and the most common ingested drug was acetaminophen (27.5\%), scorpion bite $(9.8 \%)$ was the second most common non-drug intoxication in CIC (Table II). The median injury severity score (ISS) for trauma patients $(n=44)$ was 6 , of which only $9.1 \%(n=4)$ had a high ISS score (ISS $>11)$ (Table II). Three of those patients died at the ED, all of the remaining trauma patients were admitted to the pediatric intensive care unit (PICU).
Table II. Diagnosis of children who arrived by EMS.

\begin{tabular}{|c|c|}
\hline Toxicity & $51(22.5)$ \\
\hline Ingestion & $34(66.7)$ \\
\hline Acetaminophen & $14(27.5)$ \\
\hline NSAI & $6(11.8)$ \\
\hline Antidepressant & $8(15.6)$ \\
\hline Multidrug & $6(11.8)$ \\
\hline Organophosphates & $4(7.8)$ \\
\hline Rodenticide poisoning & $3(5.9)$ \\
\hline Carbon monoxide poisoning & $2(3.9)$ \\
\hline Scorpion bite & $5(9.8)$ \\
\hline Snake bite & $3(5.9)$ \\
\hline Trauma & $44(19.4)$ \\
\hline ISS>11 & $4(9.1)$ \\
\hline ISS $\leq 11$ & $40(90.9)$ \\
\hline Medical emergencies & $132(58.1)$ \\
\hline Respiratory & $36(15.8)$ \\
\hline Bronchopneumonia & 19 \\
\hline Acute bronchiolitis & 7 \\
\hline Asthma attack & 4 \\
\hline Tracheostomy patient & 4 \\
\hline Foreign body in respiratory tract & 2 \\
\hline Infectious diseases & $25(11)$ \\
\hline Sepsis / septic shock & 11 \\
\hline $\begin{array}{l}\text { CNS infection (meningitis/ } \\
\text { encephalitis) }\end{array}$ & $13(9 / 4)$ \\
\hline Hepatitis A & 1 \\
\hline Neurological & $23(10.1)$ \\
\hline Status epilepticus & 18 \\
\hline Febrile status epilepticus & 2 \\
\hline Intracranial hemorrhage & 2 \\
\hline Guillain-Barré syndrome & 1 \\
\hline Cardiac & $10(4.3)$ \\
\hline Cardiomyopathy / Heart failure & 6 \\
\hline Cardiac arrest & 2 \\
\hline SVT & 2 \\
\hline Endocrinological & $6(1.1)$ \\
\hline Diabetic ketoacidosis & 5 \\
\hline Hypoglycemia & 1 \\
\hline Gastrointestinal & $4(3.8)$ \\
\hline Bleeding & 3 \\
\hline Esophagus atresia & 1 \\
\hline Non-traumatic surgical & $4(4.1)$ \\
\hline Splenic rupture & 1 \\
\hline Duodenum perforation & 1 \\
\hline $\begin{array}{l}\text { Corrosive substance ingestion/ } \\
\text { inhalation }\end{array}$ & 2 \\
\hline Other & 24 \\
\hline
\end{tabular}

NSAI: non-steroid anti-inflammatory, SVT: supraventricular tachycardia,

CNS: central nervous system, VP: ventriculo-peritoneal 


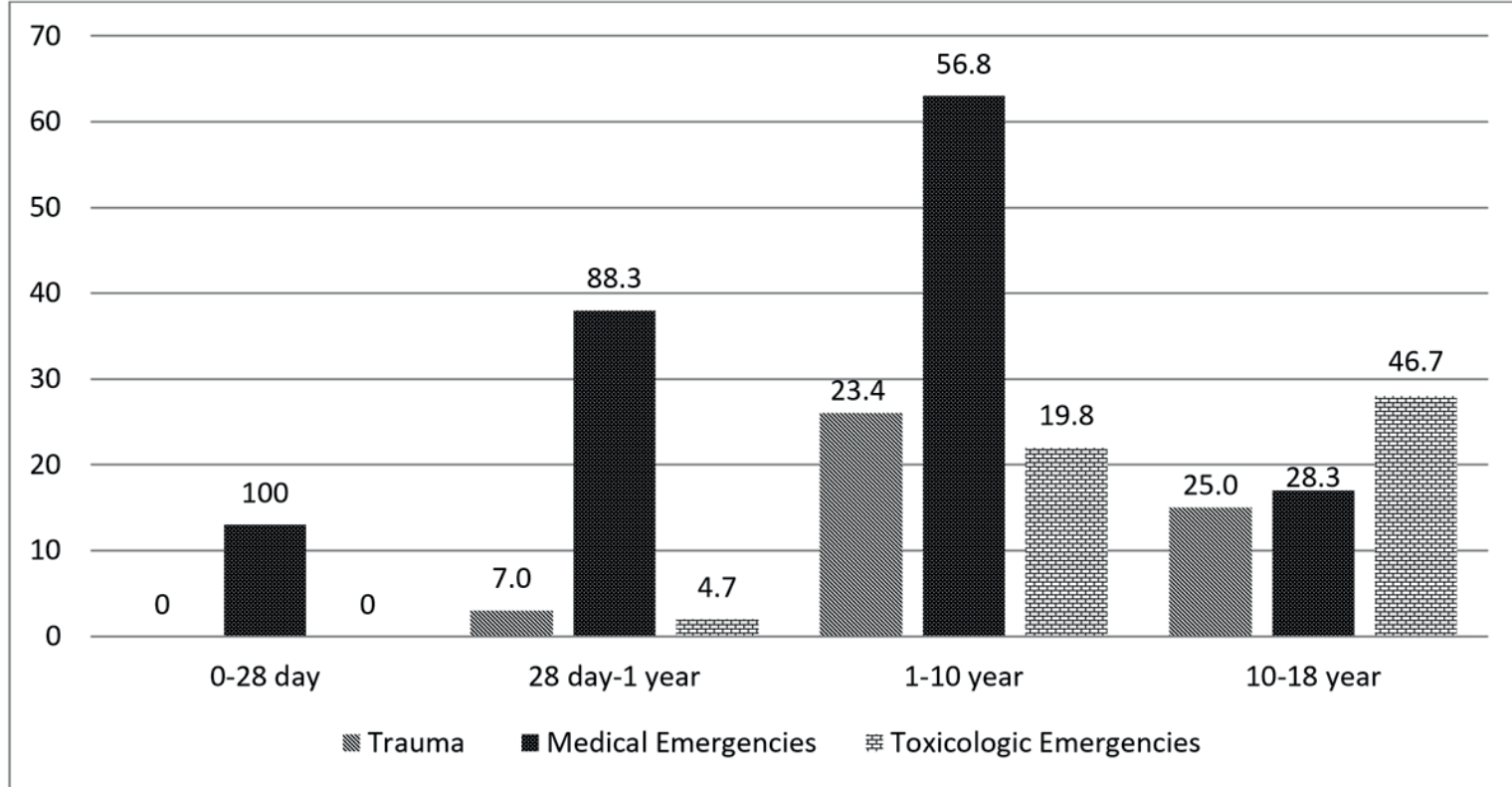

Fig. 1. Percentage (\%) of diagnosis distrubutions by age groups.

For the secondary analysis, we collected information on pre-hospital procedures for all patients arriving by EMS. Although $86 \%(n=195)$ of children underwent procedures during transport by EMS providers, no procedure was performed for 32 (Table III). Of those 32 patients, 12 had respiratory failure, 5 had sepsis/ septic shock, 5 had intoxication, 4 had status epilepticus, 2 had trauma (one of them had epidural hematoma), 2 had a scorpion bite, one had supraventricular tachycardia and other one had cardiopulmonary arrest. Most procedures were performed on children aged one or older (Table III) $(\mathrm{p}<0.001)$. Results showed that if the EMS did not have a physician, prehospital providers were less likely to provide immediate LSIs (Table IV) $(p<0.001)$. No procedure was performed in the ambulance for nearly one- third of patients $(7 / 25)$ who received immediate LSIs such as CPR and intubation in the ED (Table III).

The survival rate did not differ when the referral site and performed LSI was compared with short-term outcome (Table V). Table VI shows the clinical features of nine patients who were brought by ambulance and subsequently died (three of these died on route). There were severe trauma in 3, cardiogenic shock with congenital cardiac disease in 2, respiratory failure in 2 and septic shock in 2 non-survived patients. Four of 9 patients who died were not informed by telephone before arrival to the receiving facility. A vascular line was present in 8/9 (no intraosseous lines), intubation was performed in 5 and CPR in one patient.

Table III. EMS procedures (\%) of critically-Ill-children.

\begin{tabular}{lcccccccc}
\hline $\begin{array}{l}\text { Age } \\
\text { group }\end{array}$ & $\begin{array}{c}\text { Vascular } \\
\text { access }\end{array}$ & $\begin{array}{c}\text { Blood glucose } \\
\text { monitoring }\end{array}$ & $\begin{array}{c}\text { Given } \\
\text { medication }\end{array}$ & $\begin{array}{c}\text { BVM } \\
\text { ventilation }\end{array}$ & $\begin{array}{c}\text { Endotracheal } \\
\text { intubation }\end{array}$ & CPR & $\begin{array}{c}\text { No procedures } \\
\text { on EMS }\end{array}$ & $\begin{array}{c}\text { Total } \\
\text { patient (n) }\end{array}$ \\
\hline $0-28 \mathrm{~d}$ & 53.8 & 38.5 & 0 & 7.7 & 7.7 & 0 & 30.8 & 13 \\
28d-1y & 58.1 & 16.3 & 7.0 & 2.3 & 2.3 & 2.3 & 30.2 & 43 \\
$1-10 \mathrm{y}$ & 81.1 & 8.1 & 3.6 & 4.5 & 2.7 & 0.9 & 8.1 & 111 \\
$10-18 \mathrm{y}$ & 80 & 13.3 & 10 & 1.7 & 1.7 & 0 & 10 & 60 \\
\hline
\end{tabular}

*d: day, BVM: bag-valve-mask, CPR: cardiopulmonary resuscitation, EMS: emergency medical service. 
Table IV. Comparison of transported patients who received life-saving interventions based on referral sites.

\begin{tabular}{|c|c|c|c|c|c|c|}
\hline \multirow[b]{3}{*}{ Referred from } & \multicolumn{5}{|c|}{ Life-saving-interventions } & \multirow{3}{*}{$p$} \\
\hline & \multicolumn{2}{|c|}{ Physician } & \multicolumn{2}{|c|}{ Paramedic + AEMT } & \multirow[t]{2}{*}{ Total (n) } & \\
\hline & Yes & No & Yes & No & & \\
\hline Home & 3 & 0 & 5 & 16 & 24 & \\
\hline Scene & 3 & 1 & 9 & 13 & 26 & \\
\hline Primary care hospital & 1 & 1 & 0 & 3 & 5 & $<0.001$ \\
\hline Secondary care hospital & 17 & 6 & 22 & 85 & 130 & \\
\hline Tertiary care hospital & 4 & 6 & 4 & 18 & 32 & \\
\hline Private hospital & 3 & 1 & 2 & 4 & 10 & \\
\hline Total patients (n) & 31 & 15 & 42 & 139 & 227 & \\
\hline
\end{tabular}

*AEMT: ambulance and emergency care technician. § p values were determined with Student's t-test for continuous variables. Chi square tests or Fischer's exact tests for categorical data where appropriate.

Table V. The relationship between life-saving-interventions and staff on the EMS with mortality in criticallyIll-children.

\begin{tabular}{|c|c|c|c|c|c|c|}
\hline & \multicolumn{2}{|c|}{$\begin{array}{l}\text { Life-saving interventions on the } \\
\qquad \text { EMS }[\mathrm{n}(\%)]\end{array}$} & \multicolumn{2}{|c|}{$\begin{array}{l}\text { EMS Staff } \\
{[\mathrm{n}(\%)]}\end{array}$} & \multirow[t]{2}{*}{ Total } & \multirow{2}{*}{$p$} \\
\hline & Yes & No & Physician & Paramedic + AEMT & & \\
\hline Non-survived & $7(9.6)$ & $2(1.3)$ & $3(6.5)$ & $6(3.3)$ & 9 & $<0001$ \\
\hline Alive & $66(90.4)$ & 152 (98.7) & $43(93.5)$ & $175(96.7)$ & 218 & -0.001 \\
\hline Total & 73 & 154 & 46 & 181 & 227 & \\
\hline
\end{tabular}

EMS: emergency medical service, AEMT: ambulance and emergency care technician. ${ }^{*} \mathrm{p}$ values were determined with Fischer's exact tests.

\section{Discussion}

One of the most selected forms of misuse involving EDs is the misuse of EMS. Research has shown that in several areas of the United States as well as in Canada, Sweden, and England, the rate of inappropriate ambulance use is $40 \%$ to $50 \% .{ }^{9,10,11,12}$ Excess uses of EMS among pediatric patients with a variety of low acuity conditions have been demonstrated. Our study showed that around $90 \%$ of patients brought by ambulance did not have high acuity conditions upon arrival to the EDs. The potential adverse consequences of non-urgent EMS use include increased ED crowding, and limits rapid ambulance response for patients whose condition requires immediate care and LSI. However, critically ill patients who would likely benefit from rapid prehospital care, are under-utilizing these services like our results showed. ${ }^{13-15}$
The referral system in Turkey plays a major role in managing the flow of patients from primary to secondary and tertiary care hospitals (as the health care system structure is based on those three levels). All secondary care hospitals in Turkey have at least two pediatricians and provide medical care upon referral by a primary care physician and that requires more specialized knowledge, skill, or equipment than the primary care physician can provide. Since those hospitals do not have well-structured pediatric intensive care unit (PICU) we believe that CIC deserve to be referred. The explanation for referral from tertiary ED to another tertiary facility may the inadequate number of PICU and limited bed capacity. Although, guidelines exist concerning the timing of transfer, for certain groups of patients and the decision to transfer should be made by consultants after full assessment and discussion between referring and receiving EDs. The current study showed that $40 \%$ of CIC were brought to EDs without 


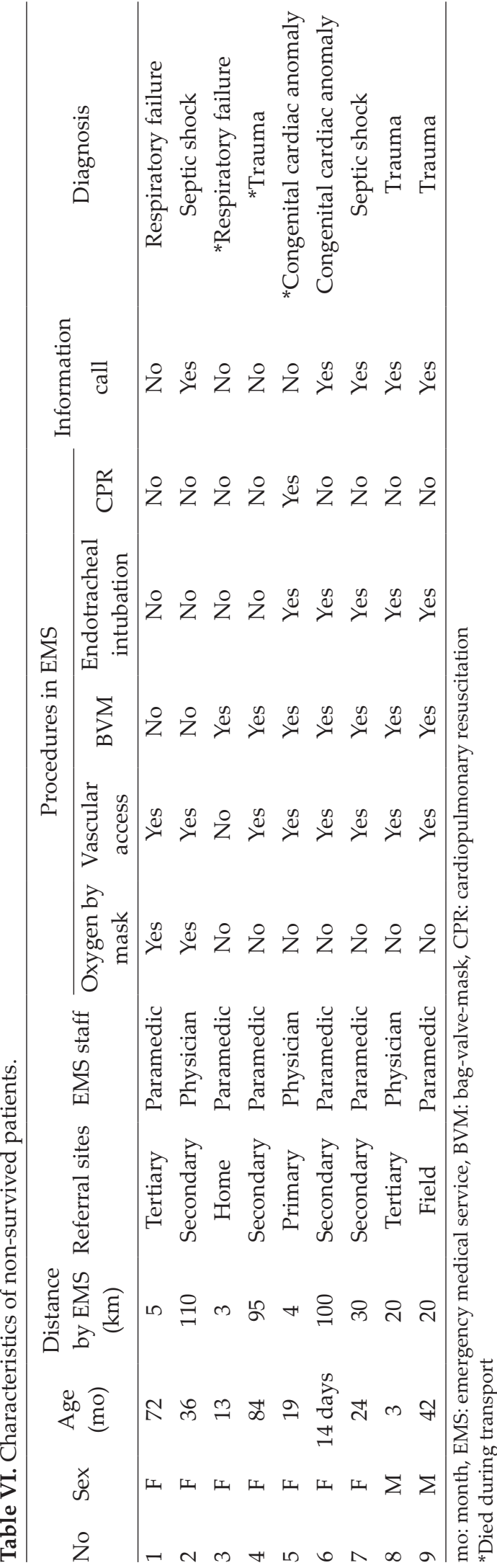

information calls. This improper referral leads to poor outcome of high acuity medical conditions. ${ }^{16}$ Local policies should be prepared to show referral patterns, available expertise, and clinical circumstances.

A previously published report indicated that children older than 7 years old were more likely to be transported by EMS due to trauma and intoxication, although infants transported by ambulances were predominantly for other medical emergencies. ${ }^{17}$ Similarly, in a Canadian study medical emergencies represented the majority of cases of EMS under two years of age, trauma being the most common reason in children over nine. ${ }^{18}$ The majority of EMS transports in our groups were traumatic and toxicological emergencies $(80 \%)$ rather than medical illness (20\%) in older age groups.

The most common pre-hospital pediatric procedures are cervical spine immobilization, vascular line, and basic and advanced airway management. ${ }^{8}$ Although the Turkish Ministry of Health authorizes paramedics and AEMT to perform all the procedures listed above, in our study many CIC who needed immediate LSI did not receive any procedure. Some patients who required immediate vascular line (Supraventricular tachycardia, status epilepticus, altered mental status, respiratory failure) were brought to the ED without prehospital procedure. We can explain this by the difficulty of establishing the vascular line in a pre-hospital setting especially in younger, less cooperative children. Paramedics and AEMT receive very limited training compared to physicians, and most rarely have to manage seriously ill or injured children. ${ }^{19}$ Although EMS personnel and paramedics are responsible for performing all vital interventions in CIC, previous studies have shown that paramedics were required to provide advanced life support, such as endotracheal intubation in trauma patients, in less than $1 \%$ of cases a year. ${ }^{20-22}$

The timing of emergency procedures is of critical importance during transport, and early management can be beneficial in improving 
outcomes. ${ }^{23}$ Recent studies emphasize that the "golden hours" in pediatric transport is not important, and that misapplication of this concept can result in early and goal-directed interventions being delayed. ${ }^{24}$ EMS personnel reported feeling comfortable performing any critical procedure if they are well trained and experienced..$^{25}$ Requirements for pre-hospital pediatric resuscitation in children with medical emergencies and trauma were similarly rare in our study, and usually in children younger than 10.

Similar with previous studies the level of LSIs performed by EMS staff in this study was quite low. ${ }^{8,26}$ We believe that paramedics possessed insufficient knowledge and experience to carry out these procedures, and that they preferred to transport patients to the ED without stabilization, even in the event of respiratory or cardiac arrest. This is the most likely explanation for obviously non-survived patients, or subjects who have been pronounced dead, being transported via the EMS. In such cases, mortality cannot be prevented (since it has already occurred), and transporting such cases places the public and the EMS crew at risk of a vehicular accident in the process. In addition, there can be no benefit to the patient in transporting a dead body. Unnecessary transport of the non-survived patients restricts EMS resources for other patients who may truly benefit from them.

Our study has several limitations, including a lack of physiological data for patients at the time of pick-up (blood pressure, pulse, Glasgow coma scale, body temperature, respiratory rate, oxygen saturation, general condition, etc.), and a lack of detailed information concerning physical examination, accurate reasons for referral, some transport times, costs, and patient characteristics in the referral hospital. We also did not analyze and compare patients outcomes who received LSIs in the ED but who were not transported by ambulance.
In conclusion, this study presents comprehensive epidemiological and outcome data for CIC transferred by EMS system in Turkey. Patients transported by ambulance and referred from secondary or tertiary hospitals were more severely ill than those brought from the field or primary care facilities. When prehospital procedures for CIC were not performed higher mortality occurred. This study indicates a deficiency in Turkish pre-hospital pediatric emergency care, and we hope that our findings can assist with the development and improvement of the pediatric EMS system in Turkey. Information concerning the pre-hospital transport of pediatric cases can help improve care and prevent unnecessary resource use. Our study offers a clinical overview of pediatric emergencies that should be of assistance to EMS administrators, policymakers, and ED directors in planning for the care of acutely ill and injured children in Turkey.

\section{Acknowledgments}

The authors would like to express their sincere gratitude to the Turkish Pediatric Emergency Medical Service (TPEMS) Study Group that worked together to provide technical and writing assistance, and to the departmental heads for general support.

\section{REFERENCES}

1. Shah MN. The formation of the emergency medical services system. Am J Public Health 2006; 96: 414423.

2. Seid T, Ramaiah R, Grabinsky A. Pre-hospital care of pediatric patients with trauma. Int J Crit Illn Inj Sci 2012; 2: 114-120.

3. Al-Anazi AF. Pediatric emergency medical services and their drawbacks. J Emerg Trauma Shock 2012; 5: 220-227. 
4. Seidel JS. Emergency medical services and the pediatric patient: are the needs being met? II. Training and equipping emergency medical services providers for pediatric emergencies. Pediatrics 1986; 78: 808-812.

5. Gausche M, Lewis RJ, Stratton SJ, et al. Effect of out-of-hospital pediatric endotracheal intubation on survival and neurological outcome: a controlled clinical trial. JAMA 2000; 283: 783-790.

6. Ludwig S, Selbst S. A child-oriented emergency medical services system. Curr Probl Pediatr 1990; 20: 109-158.

7. Sariyer G, Ataman MG, Akay S, Sofuoglu T, Sofuoglu Z. An analysis of Emergency Medical Services demand: time of day, day of the week, and location in the city. Turk J Emerg Med 2016; 17: 42-47.

8. Resmi Gazete. Ambulans ve Acil Bakım Teknikerleri ile Acil Tıp Teknisyenlerinin Çalışma Usul ve Esaslarına Dair Tebliğ. http://www.resmigazete. gov.tr/eskiler/2009/03/20090326-4.htm (Accessed on December 03, 2018).

9. Morris DL, Cross AB. Is the emergency ambulance service misused? Br Med J 1980; 281: 121-123.

10. Gersan LW, Shvarch L. Emergency medical service utilization by the elderly. Ann Emerg Med 1982; 11: 610-612.

11. Brismar B, Dahlgren BE, Larson J. Ambulance utilization in Sweden: analysis of emergency ambulance missions in urban and rural areas. Ann Emerg Med 1984; 13: 1037-1039.

12. Rademaker AW, Powell DG, Read JH. Inappropriate use and unmet need in paramedic and nonparamedic ambulance systems. Ann Emerg Med 1987; 16: 553556.

13. Mosley I, Nicol M, Donnan G, Patrick I, Kerr F, Dewey $\mathrm{H}$. The impact of ambulance practice on acute stroke care. Stroke 2007; 38: 2765-2770.

14. Rokos IC, French WJ, Koenig WJ, et al. Integration of pre-hospital electrocardiograms and ST- elevation myocardial infarction receiving center (SRC) networks: impact on door-to-balloon times across 10 independent regions. JACC Cardiovasc Interv 2009; 2: 339-346.

15. Phelps MA, Rodriguez RM, Passanante M, Dresden G, Kriza K. EMS activation in a cohort of critically ill patients. J Emerg Med 2002; 22: 127-131.
16. Kulshrestha A, Singh J. Inter-hospital and intrahospital patient transfer: recent concepts. Indian J Anaesth 2016; 60: 451-457.

17. Kost S, Arruda J. Appropriateness of ambulance transportation to a suburban pediatric emergency department. Prehosp Emerg Care 1999; 3: 187-190.

18. Richard J, Osmond MH, Nesbitt L, Stiell IG. Management and outcomes of pediatric patients transported by emergency medical services in a Canadian prehospital system. CJEM 2006; 8: 6-12.

19. Jewkes F. Prehospital emergency care for children. Arch Dis Child 2001; 84: 103-105.

20. Emergency Medical Services Education Agenda for the Future: A Systems Approach. (Available at: https://www.ems.gov/ pdf/ education/ EMSEducation- for-the- Future-A- Systems-Approach/ EMS_Education_Agenda.pdf. (Accessed on December 09, 2018).

21. Hansen M, Lambert W, Guise JM, Warden CR, Mann NC, Wang H. Out-of-hospital pediatric airway management in the United States. Resuscitation 2015; 90: 104-110.

22. Su E, Mann NC, McCall M, Hedges JR. Use of resuscitation skills by paramedics caring for critically injured children in Oregon. Prehosp Emerg Care 1997; 1: 123-127.

23. Izawa J, Iwami T, Gibo K, et al. Timing of advanced airway management by emergency medical services personnel following out-of-hospital cardiac arrest: a population-based cohort study. Resuscitation 2018; 128: 16-23.

24. Stroud MH, Prodhan P, Moss MM, Anand KJ. Redefining the golden hour in pediatric transport. Pediatr Crit Care Med 2008; 9: 435-437.

25. King BR, King TM, Foster RL, McCans KM. Pediatric and neonatal transport teams with and without a physician: a comparison of outcomes and interventions. Pediatr Emerg Care 2007; 23: 77-82.

26. Ong ME, Cho J, Ma MH, et al; PAROS Investigators. Comparison of emergency medical services systems in the pan-Asian resuscitation outcomes study countries: report from a literature review and survey. Emerg Med Australas 2013; 25: 55-63. 